Interference by Pentose in Estimation of Hexose Sugars with

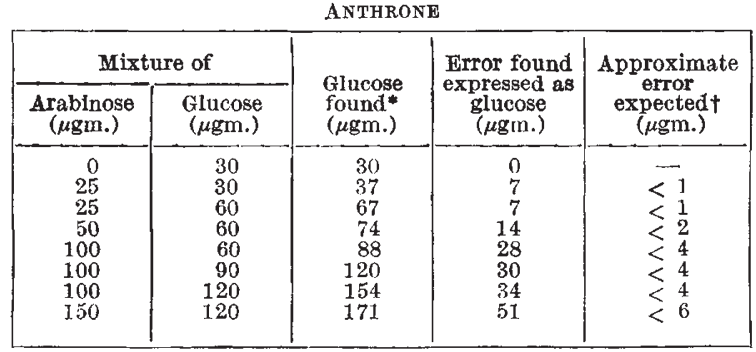
*Values read off a standard glucose graph. They are means of four
separate estimates, each based on two duplicates. The 95 per cent confldence limits to these means are given by mean \pm 1.2 per cent of the mean.

$t$ Absorption readings for various amounts of anthronated pure the standard glucose graph and expressed as glucose

sion of the arabinose was determined by measuring the colour development from a pure arabinose solution, and expressing this in terms of glucose. It was found that $100 \mu \mathrm{gm}$. of arabinose gave a colour development equivalent to less than $4 \mu \mathrm{gm}$. of glucose. The errors actually observed in solutions containing both sugars were far greater than this, approaching 30 per cent when the molecular concentration of arabinose equals that of glucose.

This finding indicates that, when using the hexoseanthrone complex in hexose sugar estimation, any pentoses present should be corrected for or removed. The procedure adopted for separation of pentose and hexose sugars from their mixtures, and the quantitative estimation of both groups, will be published elsewhere.

Division of Plant Industry,

Commonwealth Scientific and

Industrial Research Organization, Canberra.

July 28.

1 Johanson, R., Aust. J. Sci., Res., B4, 231 (1951)

${ }^{2}$ Dreywood, R., Indust. Eng. Chem., Anal. Ed., 18, 499 (1946).

${ }^{3}$ Morris, D. L., Science, 107, 254 (1948). Barnett, A. J. G., and Miller , T. B., J. Sci. Food Agric., 1, 337 (1950). Long, C., Biochem. J. E., Arch. Biochem., 25, 191 (1950)

\section{Liesegang Rings on Metallic Bases}

We have repeated the experiment described by Christomanos ${ }^{1}$, and observe the formation of good liesegang rings in all cases on clean, pure silver and other more noble metals; but either no rings, or badly distorted ones, on less noble metals and silver alloys. If the silver surface is previously darkened by exposure to sulphide, the rings are distorted but none the less appear in most cases. If, however, the clean metal is previously heated to darkening, or dipped in hydrogen peroxide solution, the rings that are eventually formed are decidedly inferior.

These observations suggest a modification of the normal ring formation by interruption of the straightforward precipitation of silver chromate, and appear to be compatible with the supersaturation theory rather than requiring an electrochemical explanation. ANDREW VANHOOK

Department of Chemistry, EDWARd J. REARDON

College of the Holy Cross, Worcester, Mass. June 28.

${ }^{1}$ Christomanos, An., Nature, 165, 238 (1950).

\section{Effects of Water Vapour on the Electrical Properties of Anodized Aluminium}

IN connexion with experiments on semiconductors, one of $u^{1}$ noted the very considerable change of capacity which took place when a condenser containing aluminium oxide as the dielectric material was placed in a system which was then evacuated. The change of capacity was ascribed to the removal of adsorbed water from the porous aluminium oxide. In the above investigation, the condenser consisted of an aluminium sheet, of an aluminium oxide layer formed electrolytically (by 'anodizing') on the sheet, and of a thin metallic layer of aluminium evaporated on to the oxide film. The aluminium sheet and the evaporated surface then formed the plates of the condenser.

We measured the capacity of a condenser formed in a similar fashion on an aluminium wire of commercial purity, of approximately $1 / 16$ in. diameter, which was placed in an enclosure in which water vapour was admitted under controlled conditions. Some measurements of the leakage resistance of the condenser were made concurrently with the capacity measurements. A typical sample of useful length $3 \mathrm{~cm}$. had a capacity of $1,200 \mathrm{pF}$. at zero humidity. The oxide layer was formed at $50 \mathrm{~V}$. in a 3 per cent chromic acid bath. The thickness of the oxide film is estimated to be about 1 micron.

A family of curves relating the capacity of the condenser to water vapour pressure at various temperatures of the condenser is shown in the accompanying graph. Several features are worthy of comment : (1) each curve may be represented by two intersecting straight lines; (2) the initial

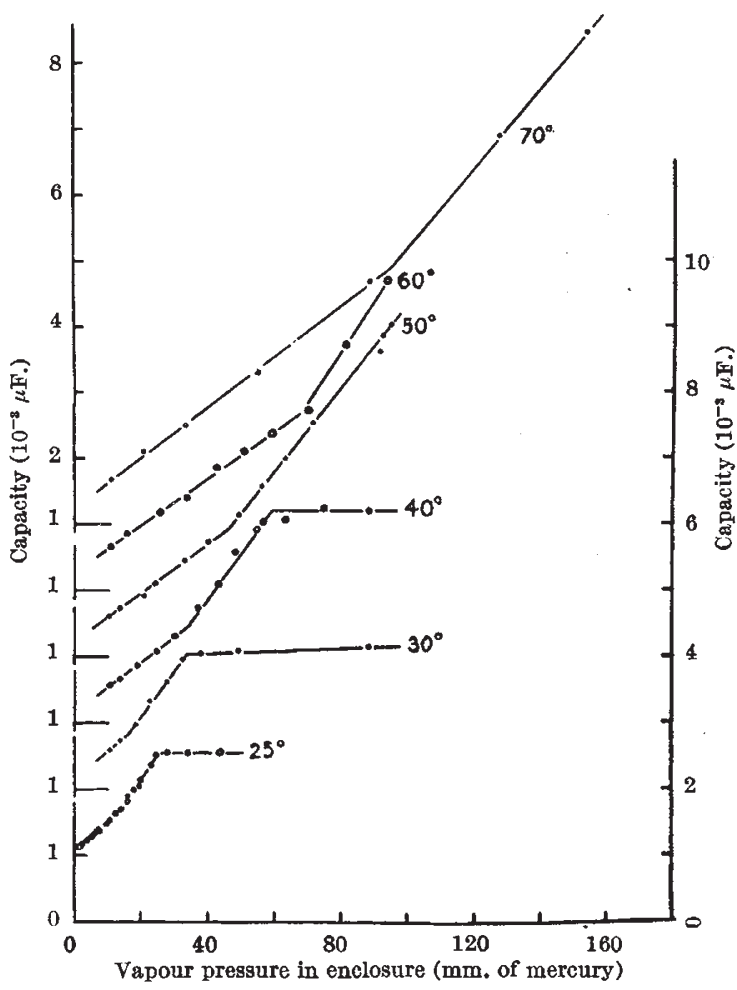

Variation of capacity with water vapour pressure in the enclosure for various temperatures of the element. (For clarity, the capacity ordinate of slivessive curves has been displaced one unit vertically) 